\title{
Relation between Emotion Adjustment and Perceived Social Support with Quality of Life of Athletes with Disability
}

\section{Gholamreza Astaraki', Farideh Ashrafganjooei ${ }^{2}$, Seyed Hamid Sajadi ${ }^{2 *}$}

'Department of Sport Management, College of Physical Education and Sport Sciences, Central Tehran Branch, Islamic Azad University, Tehran, Iran

${ }^{2}$ Department of Sport Management, College of Physical Education and Sport Sciences, Islamic Azad University, Central Tehran Branch, Iran

Study Area:Tehran, Iran

Coordinate: $35^{\circ} 41^{\prime} 46^{\prime \prime} \mathrm{N}$; $51^{\circ} 25^{\prime} 23^{\prime \prime} \mathrm{E}$

Keywords: Public sympathy, Social security, Feeble

\section{Abstract}

The relationship between emotional cognitive adjustment and perceived social support and determining the share of each one of these variable in quality of life for disabled athletes is an important factor to know. We selected 100 people among disabled athletes through convenience sampling and were asked to fill emotional cognitive adjustment strategies scale questionnaire, perceived social support questionnaire and quality of life scale. Results revealed that social support parameters have significant relation with parameters required for quality of life. Similarly, all the parameters regarding emotional cognitive adjustments (except perspective taking) revealed positive and significant relation with all parameters of quality of life (including physical, psychological, interpersonal relation and environment). However, the perspective taking parameter has only positive and significant relation with psychological dimension of quality of life, and it has no significant relation with other dimensions. Meanwhile, negative parameters of emotional cognitive adjustment, self-blaming and catastrophic thinking has no significant relation with any parameters of quality of life. Rumination has only negative significant relation with interpersonal relation dimension of quality of life and blaming others parameter had negative and significant relation with the environment. Results of stepwise regression table show that among studies parameters, positive refocusing and important people are in the regression equation. In nutshell, positive refocusing and social support of influenced people impart to raise their quality of life.

competitions for disabled people, extensive competitions like Paralympic games are held for disabled athletes in which they are actively participating (Stuart, 2001). Disabled people are a part of our society since the emergence of humankind. With qualitative and quantitative development of disability, and acceptance of disabled people as members of society, disability of noticeable and famous people all caused that a portion of efficient force of medicine and physical exercise of governments takes initiatives for wellness of disabled people and improvement of their quality of life by assigning budget and using technology (Safania \& Mokhtari, 2012). In this paper, a relation between emotional adjustment and perceived social support on 
quality of life of disabled athletes is studied. Nowadays, the outcome of science and technology are used in its best manner for achieving the better life. Meanwhile, physical education (PE) is also gaining momentum as a sub-branch of sciences in various developed countries. PE as a natural, social and educational aspect need a great mission in physical and psychological development of people and aims to develop the personality and psychosocial growth in all human dimensions.

The term of quality of life refers to satisfaction of life and welfare (Badner et al., 2010). Today, quality of life required for any services and assigning resources are the matter of analysis (Katschnig \& Krautgartner, 2002). The concept of perceived social support deals with support in terms of individual cognitive evaluation from its surrounding and relation with others (Streeter \& Franklin, 1992). Many psychosocial factors can influence quality of life. One of these factors is perceived social support. Social support serves as an emotional coping mechanism with potential for affecting quality of life (Ersoy \& Güldü, 2005). Adjusting emotions influences on quality of life (Cakmak et al., 2010). There is a relation between quality of life and perceived social support. It has been seen in chronic patients, as perceived social support is increased, their quality of life would become better. Findings of researchers show that perceived social support can prevent the occurrence of undesirable physiologic morbidity, increase the self-care and self-conf idence and have the positive effect on the physical and psychosocial status and clearly increase performance and improvement of the quality of life (Roberts \& Gotlib, 1997). Göz et al. (2007) has concluded that social support, especially from friends and family, can predict the quality of life. Michaeli et al. (2012) in a study have drawn the conclusion that various aspects of perceived social support, coping strategies and tolerance have positive correlation with quality of life.

Filazoglu \& Griva (2008) while examining the relation between coping styles and social support and quality of life of women with breast cancer found out that coping styles were related to quality of life and problem-based coping style had positive relation with quality of life. Unfortunately, research carried out in the context of standards of the sport ventures are scarce and limited therefore whatever available have been reviewed.

History of physical exercise of disabled people in Iran: before Islamic revolution, the federation of disabled war veteran exercise was an inactive committee under the supervision of medical federation and the activity of this committee was limited merely on its incumbents participating in international conferences and failed to undertake any activity among disabled people. After Islamic revolution of 1979 , from the beginning of 1980 , the federation of disabled people exercise has been founded.
The very first activity of this newly founded federation was dispatching a group to matches of Olympic for disabled people in Netherlands at the summer of 1980 aiming to gain the technical experiences and getting insight into regulations and participating in conference of disabled people exercise for making the Islamic republic of Iran known to international federation of disabled people.

History of emotional adjustment: structure of emotional adjustment was introduced for the first time in development literature as a framework which considers the difference between emotions in favour of effective processes and other emotions; for example, time, duration, intensity etc. (Thompson, 1994). Emotion adjustment doesn't aim to remove incompatible feeling and replacing compatible emotions, yet it aims to establish the dynamic effectiveness of each one of emotions for bringing about a compatible response to the environment.

Perceived social support: it refers to the cognitive evaluation of availability and sufficiency of support by others. The main function of perceived social support is to believe to being respected and noticed due to subjective evaluation and expectations of supporting and deems itself as a member of mutual duties net (Carron, 1982).

History of quality of life: life quality term has been used for the first time in 1920 by Piego in his Economy and Wellness book. Over time, researchers noticed that quality of life is one of the important consequences in people life as the WHO also underscored this definition (Fayers \& Machin, 2002).

\section{Methodology:}

Selecting methodology of research depends on nature of the subject, objectives of the study, ethical considerations ruling on the study subject, operational scope and facilities (Naderi, 1992). Therefore, based on study objective which was determining the relation between emotional adjustment and perceived social support with the quality of life of athletes having some disability, information was collected and analysed by selecting the appropriate method. This study was the descriptive correlative type. In this paper, three-variable correlation parameters were used. The statistic population of the study consists of all disabled athletes across the country. In this study, the convenient non-stochastic sampling method was used. The sample is defined as a group of society member by which the required information of study are acquired and is a sub-society selected from entire society and stands for it (Delavar, 2012). Sample members are disabled athletes of Tehran. Since this study is correlative, the size of the sample which represents the society should be at least 50 people (Delavar, 2012). To this end, 100 people were selected from disabled athletes. 
Tools for obtaining study data consisted of three questionnaires: 1) emotional cognitive adjustment strategic scale, 2) multidimensional scale of perceived social support (MSPSS), 3) quality of life questionnaire (WHOQOL:BREF).

Emotion cognitive adjustment strategies scale by Streeter \& Franklin, (1992) was provided for evaluating the manner of thinking after experiencing threatening or stressor event in life. This scale has 36 items and it is answered based on Likert five-degree scale.

Multidimensional scale of perceived social support (MSPSS): it is a 12-phrase tool for evaluating the perceived social support is provided from three resources: family, friends and important people in life. This scale measures the amount of perceived social support by the respondent in each one of mentioned contexts and has three subscales, namely family (phrases 3,4,8, 11), friends (Phrases 6,7, 9, 12 ) and important people $(1,2,5,10)$. It is a brief, simple and affected by time tool, therefore, it is widely used in many studies. WHOQOL: BREF questionnaire: for integration of studies and measuring Quality of Life, WHO missioned a group for making a questionnaire. The product of group activity was a quality of life questionnaire with 100 questions (WHOQOL-10o), a few years later, for using it more easily, a brief form of it has been devised.

Statistic methods of correlation and regression have been used for data analysis with respect to hypothesis and questions. For examining the study hypothesis, at first Pearson correlation and then stepwise regression were used.

\section{Results:}

\section{Results are summarized in Table-1 to Table- 6 .}

Table-1: Coeff icient of correlation of perceived social support and its parameters with that of Quality of life

\begin{tabular}{|c|c|c|c|c|c|c|c|c|}
\hline & 1 & 2 & 3 & 4 & 5 & 6 & 7 & 8 \\
\hline \multicolumn{9}{|c|}{$\begin{array}{ll}1 & 1\end{array}$} \\
\hline \multirow[t]{2}{*}{2} & ** 0.372 & 1 & & & & & & \\
\hline & 0.000 & & & & & & & \\
\hline \multirow[t]{2}{*}{3} & ${ }^{* *} 0.507$ & ** 0.625 & 1 & & & & & \\
\hline & 0.000 & 0.000 & & & & & & \\
\hline \multirow[t]{2}{*}{4} & **o.614 & ${ }^{* *} 0.536 *$ & **o.694 & 1 & & & & \\
\hline & 0.000 & 0.000 & 0.000 & & & & & \\
\hline \multirow[t]{2}{*}{5} & 0.164 & ${ }^{* *} 0.364$ & ** 0.333 & ${ }^{* *} 0.314$ & 1 & & & \\
\hline & 0.102 & 0.000 & 0.001 & 0.001 & & & & \\
\hline \multirow[t]{2}{*}{6} & 0.192 & ${ }^{* *} 0.468$ & ** 0.366 & ** 0.421 & **o.866 & 1 & & \\
\hline & 0.055 & 0.000 & 0.000 & 0.000 & 0.000 & & & \\
\hline \multirow[t]{2}{*}{7} & 0.166 & ${ }^{* *} 0.331$ & ${ }^{* *} 0.281$ & ${ }^{*} 0.231$ & **o.853 & **o.614 & 1 & \\
\hline & 0.100 & 0.001 & 0.005 & 0.021 & 0.000 & 0.000 & & \\
\hline \multirow{2}{*}{8} & 0.098 & ${ }^{* *} 0.288$ & ** 0.276 & * 0.217 & **0.911 & **0.712 & **0.701 & 1 \\
\hline & 0.330 & 0.004 & 0.005 & 0.030 & 0.000 & 0.000 & 0.000 & \\
\hline
\end{tabular}

1 physical; 2- psychological; 3- relations; 4- environment; 5General support; 6- Important people; 7-family; 8- friends.

** : correlation at level of signif icance 0.01 ;

*: correlation at level of signif icance 0.05
Considering table 1 , parameters of perceived social support have significant relation with all parameters of quality of life except physical parameter. In other words, general social support has significant and positive relationship with the psychological parameter of quality of life with correlation coefficient (o.364), relations parameter with correlation coefficient (o.333), and environment parameter with correlation coefficient (o.314). However, the physical parameter of quality of life with the correlation coeff icient (o.164) has no significant relation. Other perceived social support parameters including important people, family and friends also have significant and positive relation with psychological, interpersonal relation and environmental parameters, however, no significant relation has been found with the physical parameter of quality of life.

Table-2: table of correlation coeff icient of emotional cognitive adjustment parameter with parameters of quality of life

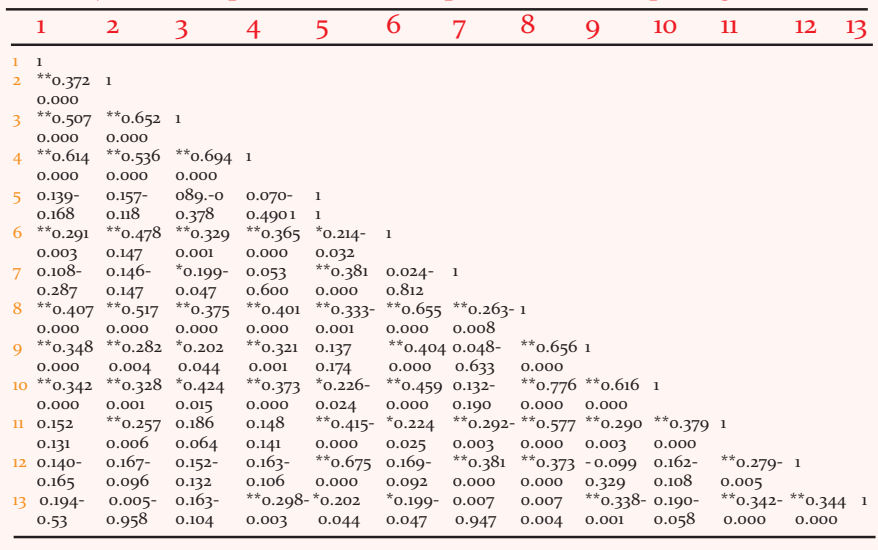

- physical; 2- psychological; 3- relations; 4- environment; 5- selfblaming; 6-acceptance; 7-rumination; 8-Positive concentration; 9-focus on plan; 10-Positive evaluation; 11-perspective taking; 12 -Catastrophic thinking;13-Blaming others

Considering table-2, all the parameters of emotional cognitive adjustment except perspective-taking (including acceptance, positive refocusing, and focus on planning and positive evaluation) have positive and significant (including physical, psychological, interpersonal relation and environment) effects. However, the parameter of perspective-taking has positive and significant relation only in the psychological dimension of quality of life and has no signif icant relation to other dimensions. Among negative parameters of emotional cognitive adjustment (including catastrophic thinking, rumination, self-blaming, and blaming others), rumination parameter only has negative and significant relation with interpersonal relation parameter of quality of life with correlation coeff icient of (-o.199) and blaming others has significant and negative relation with environment variable, correlation coeff icient (-0.298). 
Table-3: Regression table of prediction of quality of life considering the perceived social support parameters and emotional cognitive adjustment

\begin{tabular}{llllll}
\hline Model & variable & $\begin{array}{l}\text { Non SRC } \\
\text { B }\end{array}$ & $\begin{array}{l}\text { SRC } \\
\text { Beta }\end{array}$ & $\mathrm{t}$ & significance \\
\hline 1 & Positive & 44.13 & & 7.87 & 0.0001 \\
& refocusing & 2.41 & 0.51 & 5.87 & 0.0001 \\
2 & Positive & 38.66 & & 6.77 & 0.0001 \\
& refocusing & 1.82 & 0.386 & 4.12 & 0.0001 \\
& Important & & 6.77 & & \\
& people & 1.18 & 0.276 & 2.94 & 0.004 \\
\hline
\end{tabular}

Results of stepwise regression table showed that among studied parameters, positive refocusing parameters and important people are incorporated into a regression equation. In other words, positive refocusing and important people's social support in life has the power of predicting the quality of life.

Descriptive findings (demographic findings): participants in the study were 100 people with disability who visits gymnasiums of Tehran or House of Disabled People. All the participants were male with age range between 15 and 35 . The education level of participants was high school diploma to Master of Science.

Table-4: distribution of groups based on degree of educations

\begin{tabular}{lll}
\hline Education diploma & No. & Percentage \\
\hline High school diploma & 30 & $30 \%$ \\
Associate degree & 25 & $25 \%$ \\
Bachelor & 35 & $35 \%$ \\
Master of Science and higher & 10 & $10 \%$ \\
\hline \multicolumn{2}{l}{ Table-5: Distribution of groups based on socioeconomic status } \\
\hline \multicolumn{2}{l}{ percentage } \\
\hline Low & No. & $25 \%$ \\
Hiddle & 25 & $53 \%$ \\
\hline
\end{tabular}

Above table shows that greatest frequency in socioeconomic status for the middle class. In this section, descriptive findings of variables have been addressed.

Table 6: variables descriptive information (n: 100)

\begin{tabular}{lll}
\hline & Average & SD \\
\hline General perceived social support & 36.84 & 1.07 \\
Important people & 11.12 & 3.96 \\
Family & 13.27 & 4.03 \\
Friends & 12.43 & 4.18 \\
Physical & 20.59 & 4.41 \\
Psychological & 19.76 & 4.61 \\
Interpersonal relation & 10.54 & 3.27 \\
Environment & 25.02 & 8.19 \\
Self-blame & 12.72 & 3.45 \\
Acceptance & 12.44 & 3.68 \\
rumination & 12.84 & 2.6 \\
Positive refocusing & 12.44 & 3.6 \\
Focus on planning & 14.26 & 3.18
\end{tabular}

Positive evaluation $\quad 13.12 \quad 3.11$ $\begin{array}{lll}\text { perspective-taking } & \mathbf{1 2 . 4 6} & 3.03\end{array}$ $\begin{array}{lll}\text { Catastrophicthinking } & \mathbf{1 2 . 5 2} & 3.74\end{array}$ $\begin{array}{lll}\text { Scorning others } & 10.68 & 3.95\end{array}$

Among mentioned parameters, general perceived social support revealed the highest average (36.84) and interpersonal relation showed the lowest average (10.54). Similarly, the environment parameter revealed the greatest SD (8.19) and general perceived social support shown the lowest SD (1.07).

\section{Conclusion:}

Considering the obtained results, this study shows that within disabled athletes, perceived social support has relation with all parameters required for quality of life (except physical parameter). In nutshell, perceiving social support in disabled people increases their quality of life in psychological, interpersonal relation and environmental factors. This study is consistent with some previous research and showed that perceived social support plays a leading role in quality of role (Heidarzadeh et al, 2013). This study showed that positive and adaptive parameters of emotional cognition adjustment have stronger relation with quality of life than negative and non-adaptive parameters of emotional cognitive adjustment. Conclusively, establishing and increasing positive parameter of emotional adjustment can decrease the relation of negative parameters. Earlier, almost similar conclusions were already drawn by Bateni (2012), Webb et al. (2015), Azar (2013), Difendruf et al. (2008) and Berking et al. (2008) regarding positive cognitive adjustment. In other word, most of the previous research had shown the relation of all parameters of emotion adjustment with the quality of life. In a general conclusion, we can say that some parameters of emotional cognitive adjustment have significant relation with quality of life. This study has some limitations such as:

- The study has been conducted with a small sampleand which is a hitch regarding generalising the study data to the studies population. -

$\square$ This study has been done in cross-section manner. For this reason, it makes the conclusion difficult about the causality. -

- Lack of control of other influential variables is among main limitations of this study.

It is proposed to conduct this study as the effectiveness of teaching strategies of emotional adjustment on quality of life of disabled people.

Acknowledgements:

We thank the staffs of all the particpants who had for their kind participation in this study. 


\section{References:}

Azar, Q.S. (2013): Effectiveness of strategies of emotional cognitive adjustment on reduction of alexithymia and impulsivity and increase of quality of life within men under influence of methadone in Urumiyeh. M.A. thesis, Urumieh University, literature and human science faculty.

Badner, V., Ahluwalia, K.P., Murrman, M.K., Sanogo, M., Darlington, T. \& Edelstein, B.L. (2010): A competency-based framework for training in advanced dental education: experience in a community-based dental partnership program. L. Dent. Educ., 74(2):130-139.

Bateni, P. (2012): To evaluate the effectiveness of training emotional regulation on quality of life and reduce anxiety anxious high school students. Master thesis. Payam Noor University.

Berking, M., Wupperman, P., Reichardt, A., Pejic, T., Dippel, A. \& Znoj, H. (2008): Emotion-regulation skills as a treatment target in psychotherapy. Behav. Res. Ther., 46(11):12301237.

Cakmak, A.F. \& Cevik, E.I. (2010): Cognitive emotion regulation questionnaire: Development of Turkish version of 18-item short form. Afr. J. Bus. Manag., 4(10): 2097-2102.

Carron, A.V. (1982): Cohesiveness in sport groups: Interpretations and Consideration. J. Sports. Psychol., 4:123-138.

Delavar, A. (2012): Theoretical and practical research in the humanities and social sciences. Roshd Publishers, Tehran.

Diefendorff, J. M., Richard, E.M. \& Yang, J. (2008): Linking emotion regulation strategies to effective events and negative emotion at work. L. Voca.Behav., 73(3): 498-508.

Eisenberg, N., Cumberlan, A., Spinard, T.L., Fobes, R.A. Shepard S.A., Reiser, M., Murphy, B.C., Losoya, S.H. \& Gutherie, I.K. (2001): The relations of regulation and emotionality to children's Externalizing and internalizing problem behavior. Child Dev., 72:11-34.

Ersoy-Kart, M. \& Güldü, Ö. (2005): Vulnerability to stress, perceived social support, and coping styles among chronic hemodialysis patients. Dialysis Transplant., 34(10), 662-671.

Filazoglu, G. \& Griva, K. (20o8): Coping and social support and health related quality of life in women with breast cancer in Turkey. Psychol.Health Med., 13(5):559-573.
Fayers, P.M. \& Machin, D. (200o). Quality of Life: Assessment, Analysis and Interpretation, Pub. By: Wiley Online Library.

Göz, F., Karaoz, S., Goz, M., Ekiz, S. \& Cetin, I. (2007): Effects of the diabetic patients' perceived social support on their qualityof-life. L. Clin. Nurs., 16(7):1353-136o.

Katsching, H. \& Krautgartner, M. (2002): Quality Quality of Life: A New Dimension in Mental Health Care. Pub. by Wiley online Library.

Naderi, H. (1992): Investigate the relationship between coping strategies and mental health. $\mathrm{PhD}$ thesis, University of Education and Rehabilitation Tehran.

Payne, D.D. (2012): Transformations: Treatment for Alcohol Addiction as a Process of Consciousness Expansion (Doctoral dissertation, Faculty of Graduate Studies and Research, University of Regina).

Roberts, J.E. \& Gotlib, I.H. (1997): Social support and personality in depression. In Sourcebook of social support and personality (pp. 187-214). Springer US.

Safania, A. \& Mokhtari, R. (2012). Participation in sports activities in leisure time and quality of life of activde and inactive disbled warveterans disabled people. International Research J.App. Basic Sci., 3(4):859-867.

Streeter, C.L. \& Franklin, C. (1992): Defining and measuring social support: Guidelines for social work practitioners. Res. Soc. WorkPrac., 2(1):81-98.

Stuart, G.W. (2001): Principle and Practice Psychiatric Nursing. St Louis. Pub. By: Mosby Co. p. 832.

Thompson, R.A. (1994). Emotional regulation a theme in search for definition in N.A.fox. The Developmental of Emotion Regulation Behavioral and Biological Considerations Monographs of the Society for research in Child Development. 59(2/3, Serial No. 240), 25-52. Chicago, Ill.

Webb, T. L., Miles, E. \& Sheeran, P. (2012): Dealing with feeling: a meta-analysis of the effectiveness of strategies derived from the process model of emotion regulation. Psychol. Bull., 138(4):775-808. 